\title{
REGENERAÇÃO DE PLANTAS A PARTIR DE SEGMENTOS DE BASE DE FOLHAS EM AVEIA ${ }^{1}$
}

\author{
REGENERATION OF PLANTS DERIVED FROM OAT LEAF BASE \\ SEGMENTS ${ }^{1}$
}

\section{Caren Regina Cavichioli Lamb ${ }^{2}$ Sandra Cristina Kothe Milach ${ }^{3}$ Giancarlo Pasquali $^{4}$ Raquel Santiago Barro}

\section{RESUMO}

\begin{abstract}
A regeneração de plantas in vitro é uma limitação encontrada na maioria dos cereais. Uma forma de minimizar essa dificuldade tem sido a busca de fontes alternativas de tecidos com habilidade para esse fim. O objetivo deste trabalho foi investigar o potencial e o período necessário para regeneração de plantas in vitro de genótipos brasileiros de aveia (Avena sativa L.) a partir de segmentos da base da folha. Segmentos de 1-2mm retirados do coleóptilo de genótipos de aveia foram cultivados por 21 dias em meio MS (MURASHIGE \& SKOOG, 1962) suplementado com 2,0mg $L^{-1}$ de 2,4-D (ácido 2,4diclorofenoxiacético) e, posteriormente, transferidos para meio de regeneração de plantas. Não foi encontrada variabilidade entre os genótipos quanto à capacidade de induzir calos embriogênicos e regenerar plantas a partir de segmentos da base da folha, tendo sido possivel regenerar genótipos de aveia antes considerados sem habilidade para o cultivo in vitro. $O$ uso desse explante possibilitou reduzir o tempo de regeneração de plantas de aveia para cinco meses e a não correlação entre a percentagem de embriogênese somática e regeneração de plantas indica que a embriogênese não é o único caminho de regeneração a partir desse explante.
\end{abstract}

Palavras-chave: Avena sativa L., embriogênese somática, explante.

\section{SUMMARY}

The ability for in vitro plant regeneration is limited in most of the cereal crops. One way to minimize this problem has been to search for alternative sources of tissues with the ability for in vitro cultivation. This report aims at the investigation of the potential and the amount of time necessary for in vitro plant regeneration of Brazilian oat (Avena sativa L.) genotypes from leaf base segments. One to two millimeter coleoptile segments of oat genotypes were cultivated for 21 days on MS medium (MURASHIGE \& SKOOG, 1962) plus 2,0mg $L^{-1}$ de 2,4-D (2,4dichlorophenoxyacetic acid), and transferred to plant regeneration media. Variability among genotypes for somatic embryogenesis and plant regeneration from leaf base segments was not found, but it was possible to regenerate oat genotypes previously considered recalcitrants for in vitro regeneration. Besides that, it was possible to reduce to 5 months the plant regeneration period with this explant. The non-significant correlation between the percentage of somatic embryogenesis and plant regeneration indicates that the embryogenesis is not the only way for plant regeneration from this explant.

Key words: Avena sativa L., somatic embryogenesis, explant.

\section{INTRODUÇÃO}

Os sistemas de cultivo in vitro utilizados para a aveia são fortemente dependente do genótipo (BRETIZGER et $\boldsymbol{a l}$., 1995), o que limita o seu uso para a transformação genética deste cereal. Desta forma, a escolha do tecido-alvo que permita regenerar o maior número de genótipos é fundamental para a obtenção de plantas transgênicas férteis em aveia (SOMERS et al., 1996; HANDEL et al., 1997).

A regeneração de aveia em cultura de tecidos foi primeiramente relatada por CARTER $\boldsymbol{e t}$ al .

\footnotetext{
${ }^{1}$ Trabalho extraído da dissertação de mestrado do primeiro autor, com bolsa do CNPq apresentada ao Curso de Pós-graduação em Fitotecnia, Universidade Federal do Rio Grande do Sul, (UFRGS).

${ }^{2}$ Bióloga, Mestre em Fitotecnia, UFRGS, RS

${ }^{3}$ Engenheiro Agrônomo, Ph.D, Professor do Departamento Plantas de Lavoura, Faculdade de Agronomia, UFRGS, CP 776, 90501-970,

Porto Alegre, RS. E-mail: milach@ vortex.ufrgs.br. Autor para correspondência.

${ }^{4}$ Farmacêutico, Ph.D, Professor do Departamento de Biotecnologia, UFRGS

${ }^{5}$ Aluno do Curso de Graduação em Agronomia, Bolsista de Iniciação Científica FAPERGS, UFRGS.
} 
(1967), com culturas iniciadas de sementes maduras. Alguns anos mais tarde, foi relatada a iniciação de calos e regeneração de plantas de aveia a partir de embriões imaturos (CUMMINGS et al., 1976; RINES \& MCCOY, 1981). Contudo, a embriogênese somática e a regeneração de plantas de genótipos brasileiros de aveia a partir de embriões imaturos foi obtida mais recentemente (BERED et al., 1996 e 1998).

SOMERS et al. (1992) e TORBERT $\boldsymbol{e t}$ al. (1995) utilizaram calos embriogênicos e culturas em suspensão produzidos a partir de embriões imaturos, para obtenção de plantas transgênicas férteis nessa espécie. Esses autores, entretanto, relataram que o tempo necessário para a obtenção de calos embriogênicos acarretou atraso significativo para a regeneração das plantas transgênicas, que foi superior a 18 meses. A conseqüência disto foi uma alta freqüência de plantas transgênicas estéreis, devido ao prolongado tempo de cultivo in vitro e a possível ocorrência de variações somaclonais que afetaram a fertilidade. Com o objetivo de reduzir o tempo para regenerar plantas transgênicas férteis, TORBERT et al. (1998) avaliaram o potencial de regeneração de plantas de aveia a partir de embriões maduros. Os autores relataram que o tempo de regeneração de plantas a partir de embriões maduros foi reduzido para 11 meses.

Por outro lado, avanço significativo foi descrito por GLESS et al. (1998a e b) com o estabelecimento de um eficiente sistema de regeneração a partir de que segmentos de base de folhas, do qual obtiveram plantas transgênicas férteis em período inferior a seis meses. A possibilidade de obter um explante que permaneça um menor período in vitro e possua capacidade de regenerar plantas é de grande interesse para a transformação genética de aveia. Contudo, não existe informação se este sistema de regeneração in vitro pode ser utilizado para genótipos brasileiros de aveia e em quanto tempo pode gerar plantas. Assim o objetivo deste trabalho foi investigar o potencial de regeneração de plantas in vitro e o período necessário de cultivo para regenerar plantas de genótipos brasileiros de aveia a partir de segmentos de base de folha. O presente trabalho é pioneiro em demonstrar que a regeneração de plantas a partir de segmento da base da folha pode ser obtida em um período curto de cinco meses com os genótipos brasileiros de aveia.

\section{MATERIAL E MÉTODOS}

\section{Material vegetal}

Três genótipos de aveia, UFRGS 19, UFRGS 930572 e UFRGS 930879-5 do Programa de Melhoramento Genético de Aveia da Universida- de Federal do Rio Grande do Sul (UFRGS) foram utilizados neste trabalho. As sementes desses genótipos foram obtidas de plantas cultivadas na Estação Experimental Agronômica (EEA/UFRGS), localizada em Eldorado do Sul/RS, em 1998. O processo de cultivo in vitro foi realizado no Laboratório de Cultura de Tecidos do Departamento Plantas de Lavoura da Faculdade de Agronomia/UFRGS.

As sementes foram desinfectadas em câmara de fluxo laminar com etanol (EtOH) $70 \%$ durante três minutos e em solução 5\% de hipoclorito de sódio $(\mathrm{NaOCl})$ comercial (com concentração de 7 a $9 \%$ de cloro ativo, segundo o rótulo), durante 20 minutos. Posteriormente foram lavadas em água destilada estéril. Após a desinfecção, as sementes permaneceram em agitador orbital por quatro horas em solução fungicida de Thiram e Baytan, nas dosagens de $2,0 \mathrm{~g} \mathrm{~L}^{-1}$ e $1,6 \mathrm{~g} \mathrm{~L}^{-1}$, respectivamente. Após, as sementes foram lavadas em água destilada estéril, sendo transferidas para vidros de germinação (Figura 1-A). Um volume de $40 \mathrm{~m} \ell$ de meio MS (MURASHIGE \& SKOOG, 1962), suplementado com 30,0g L $\mathrm{L}^{-1}$ de sacarose, $\mathrm{pH}$ ajustado para 5,8 , solidificado com 2,0g L $\mathrm{L}^{-1}$ de Phytagel $^{\mathrm{TM}}$ (Sigma Chemical CO) foi transferido para os vidros de ger-

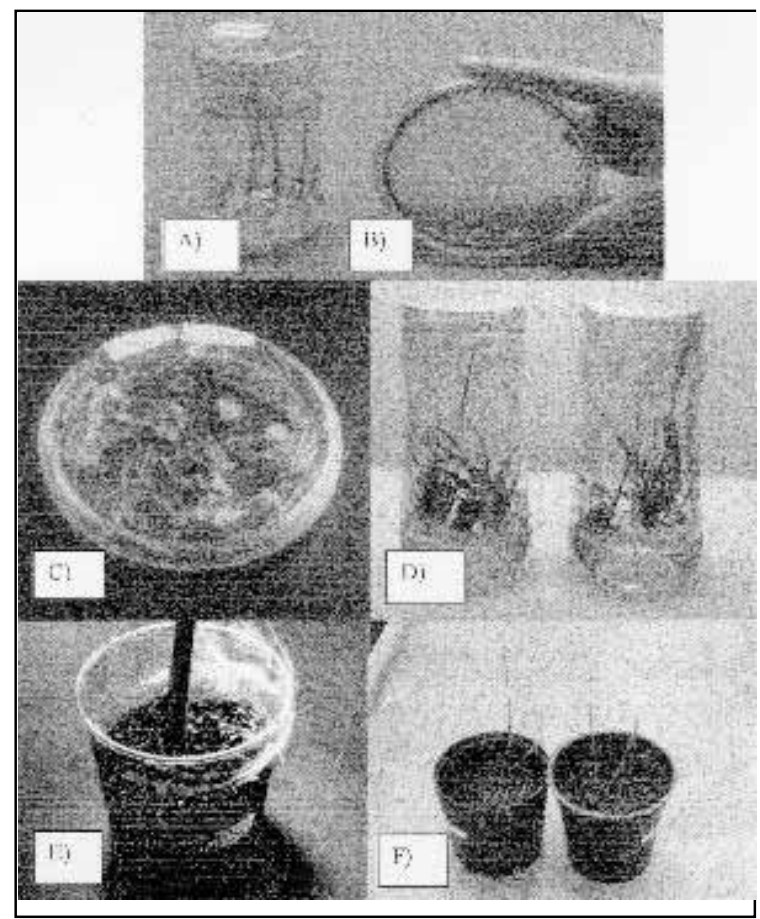

Figura 1 - A) sementes em germinação, B) segmentos da base da folha em meio de indução de calos, C) calos em meio de indução de brotos, D) brotos em meio de indução de raízes, E) plântula em período de aclimatização e F) plântulas em casa de vegetação, UFRGS, Porto Alegre, 1999. 
minação com capacidade de $250 \mathrm{~m} \ell$. Cada genótipo constava de dez repetições e cada repetição de dez sementes. Essas sementes foram colocadas em um germinador com temperatura de $22^{\circ} \mathrm{C} \pm 1^{\circ} \mathrm{C}$ e fotoperíodo de $12 \mathrm{~h} / 12 \mathrm{~h}$, permanecendo por um período de sete dias.

\section{Preparação e cultivo dos explantes}

Um segmento de 1 a $2 \mathrm{~mm}$ da base de folha de plantas jovens com altura de $2-10 \mathrm{~cm}$ foi cortado e transferido para o meio de indução de calos. Para cada genótipo, foram inoculados dez segmentos por placa de Petri, num total de dez placas (Figura 1B). As concentrações de reguladores de crescimento utilizadas nas etapas de indução de calos, parte aérea e raízes foram baseados nas estabelecidas por BREGITZER $\boldsymbol{e t}$ al. (1989) e utilizadas por GLESS et al. (1998a), e estão descritos abaixo.

\section{Meio para indução de calos}

O meio para indução de calos a partir de segmento da base da folha foi o MS suplementado com 2,0mg L $\mathrm{L}^{-1}$ de 2,4-D, 30,0g L $\mathrm{g}^{-1}$ de sacarose, $\mathrm{pH}$ ajustado para 5,8 e solidificado com $2,0 \mathrm{~g} \mathrm{~L}^{-1}$ de Phytagel $^{\mathrm{TM}}$ (Sigma Chemical CO). Os segmentos foram incubados nesse meio por 30 dias, na ausência de luz, com temperatura de $22^{\circ} \mathrm{C} \pm 1^{\circ} \mathrm{C}$. Os calos formados nesse período foram transferidos para meio de indução de brotos (Figura 1-C), após a avaliação do número de calos embriogênicos por placa.

\section{Meio para indução de parte aérea}

O meio para indução da parte aérea foi o MS, suplementado com 2,0mg L ${ }^{-1}$ de ANA (ácido $\alpha$ naftaleno acético) e $0,2 \mathrm{mg}^{-1}$ de BAP (6benzilaminopurina), 30,0 $\mathrm{g} \mathrm{L}^{-1}$ de sacarose, $\mathrm{pH}$ ajustado para 5,8 e solidificado com 2,0g L $\mathrm{g}^{-1}$ de Phytagel $^{\mathrm{TM}}$ (Sigma Chemical CO), em presença de luz direta constante, com temperatura de $22^{\circ} \mathrm{C} \pm 1{ }^{\circ} \mathrm{C}$. Aproximadamente 30 dias após permanência nesse meio, os calos que possuíam brotos foram transferidos para meio de indução de raízes e foi registrado o número de calos com parte aérea regenerada por placa.

\section{Meio para indução de raízes}

Frascos de $250 \mathrm{~m} \ell$, contendo $40 \mathrm{~m} \ell$ de meio MS sem reguladores de crescimento, suplementado com $30,0 \mathrm{~g} \mathrm{~L}^{-1}$ de sacarose, $\mathrm{pH}$ ajustado para 5,8 e solidificado com $2,0 \mathrm{~g} \mathrm{~L}^{-1}$ de Phytagel ${ }^{\mathrm{TM}}$ (Sigma Chemical CO), foram utilizados para regenerar raízes (Figura 1-D), em presença de luz direta constante, e temperatura de $22^{\circ} \mathrm{C} \pm 1^{\circ} \mathrm{C}$. Os calos que regeneraram parte aérea foram transferidos para esse meio e, após 35 dias, os segmentos que não induziram raízes foram descartados. Ao final desse período, foi registrado o número de plantas com formação de raízes antes de serem aclimatizadas.

\section{Aclimatização das plantas}

Plantas com sistema radicular formado tiveram suas raízes lavadas para eliminar qualquer resíduo de meio de cultura e foram transferidas para copos de plástico de $250 \mathrm{~m} \ell$, contendo vermiculita estéril (Figura 1-E). Na primeira semana, os copos permaneceram cobertos com filme de PVC transparente e neles a cada sete dias pequenos orifícios foram feitos, para permitir a adaptação gradativa da planta às condições ambientais. Estas plantas permaneceram na presença de luz direta constante e temperatura de $22^{\circ} \mathrm{C} \pm 1^{\circ} \mathrm{C}$ por 30 dias em sala de crescimento, sendo que após esse período foram transferidas para potes plásticos com capacidade para $5000 \mathrm{~g}$ de substrato, e depois para casa de vegetação (Figura 1-F).

\section{Delineamento experimental e análise estatística}

Foi utilizado o delineamento inteiramente casualizado, considerando cada placa de Petri como uma repetição. A análise de variância foi feita para a percentagem de calos embriogênicos, de calos que produziram parte aérea e de plantas regeneradas. A análise de correlação foi realizada para avaliar a associação entre a percentagem de calos embriogênicos e de plantas regeneradas in vitro, através do programa estatístico System Analyses Statistic (SAS, 1998). Todos os dados de contagem foram expressos em percentagens e transformados por raiz quadrada mais 0,5 para obtenção da normalidade.

\section{RESULTADOS E DISCUSSÃO}

O período de obtenção de uma planta adulta in vitro a partir de segmento de base da folha nesse trabalho foi de aproximadamente cinco meses, desde a germinação até a transferência das plantas para casa-de-vegetação. A embriogênese somática foi observada a partir de 30 dias dos segmentos em cultivo, similar ao relatado por GLESS et al. (1998a) para genótipos europeus de aveia.

Nos genótipos UFRGS 19, UFRGS 930572 e UFRGS 930879-5 a germinação das sementes ocorreu num período de sete dias, possibilitando o corte da base da folha para cultivo in vitro. A dificuldade em germinar sementes em meio de cultura não foi relatada por GLESS et al. (1998a), mas formas de evitá-la deverão ser identificadas para que essa metodologia não tenha seu uso restringido por esse problema. 
Apesar de um número modesto de estruturas embriogênicas terem sido observadas a partir de segmentos de base da folha, um número significativo de plantas foram regeneradas nos genótipos avaliados (Tabela 1, Figura 1).

A análise qualitativa de calos embriogênicos foi possível quatro semanas após a transferência dos segmentos para o meio de indução de embriogênese somática. No entanto, os setores embriogênicos não foram isolados de outros indiferenciados, sendo todos os calos transferidos de forma intacta para meio de indução de parte aérea.

A análise de variância (não apresentada) não revelou diferenças significativas entre os genótipos para embriogênese somática aos 30 dias de cultivo. Esse resultado não era esperado com base na origem diversa dos genótipos em estudo e da forte influência do genótipo em outros sistemas de cultivo in vitro. É possível, contudo, que diferenças para embriogênese somática a partir da base da folha fossem encontradas com a avaliação de um número maior de genótipos. A percentagem de calos embriogênicos variou de 13 a 27\% (Tabela 1) entre os genótipos avaliados, sendo que essas percentagens foram superiores àquelas obtidas aos 60 dias com calos originados de embriões maduros de aveia (LAMB, 2000). É interessante ressaltar, contudo, que os genótipos UFRGS 19, UFRGS 930572 e UFRGS 930879-5 apresentaram baixa freqüência de calos embriogênicos $(2 \%, 1 \%$ e $1 \%$, respectivamente) a partir de embrião maduro aos 60 dias (LAMB, 2000). Esses resultados revelam que é possível explorar o potencial de um maior número de genótipos de aveia para o cultivo in vitro pelo uso de diferentes explantes.

A indução de calos ocorreu, principalmente, onde o tecido do segmento foi ferido pelo corte realizado. Primeiramente, os calos caracterizavam-se como estruturas translúcidas, mas, a partir de duas semanas, estruturas embriogênicas começaram a se desenvolver. Em experimento piloto anterior, diferentes segmentos cortados a partir da base da folha in vitro haviam sido avaliados. Entretanto, somente o segmento mais próximo da região basal apresentou embriogênese somática, tendo sido escolhido para o presente trabalho. WERNICKE \& BRETTEL (1980) mostraram que em sorgo apenas células mais próximas do meristema possuem capacidade de induzir novamente a divisão celular. Conforme LÖRZ et al. (1988), uma característica comum entre embrião imaturo, inflorescências jovens e segmento de folhas jovens, é que esses três principais explantes utilizados em aveia possuem células meristemáticas. GLESS et al. (1998a) confirmaram, em seu trabalho com folhas de aveia, a existência de um gradiente da resposta de embriogênese somática da parte apical para a basal, indicando ser a parte basal das folhas a mais adequada para a indução e regeneração de calos.

A indução de parte aérea nos calos de segmentos da base da folha de aveia começou a ocorrer após a transferência para meio apropriado, sendo que a percentagem dos que induziram parte aérea não variou significativamente entre os genótipos investigados (Tabela 1). Também a percentagem de segmentos que formaram raízes não diferiu entre os genótipos (Tabela 1). Visualmente, a indução de raízes nesse trabalho foi diferenciada daquela obtida quando os calos foram obtidos de embrião maduro (LAMB, 2000). As raízes dos calos de base da folha apresentavam-se bastante frágeis, menos ramificadas e com pouco desenvolvimento, sendo verificado esse mesmo padrão após o período de aclimatização em vermiculita. O suplemento de $3 \%$ de sacarose, ao invés de $2 \%$, no meio de cultura pode ter dificultado a regeneração de raízes neste estudo, visto que ZHANG et al. (1996) tiveram sucesso na regeneração de raízes em aveia a partir de meristema apical em meio com $2 \%$ de sacarose. A dificuldade de regenerar raízes em aveia também foi relatada por BERED et al. (1998). Porém, quando esses autores reduziram os sais do MS para metade, a regeneração ocorreu com mais sucesso. Dessa forma, nós acreditamos que a regeneração de raízes in vitro a partir de segmento da base da folha pode ser melhorada com ajuste no meio utilizado.
${ }^{+}$Número total $(\%)$ de calos induzidos a partir de 100 segmentos de base de folha.

${ }^{\text {ns }}$ Valores não significativos a $5 \%$ pelo teste $\mathrm{F}$. 
Não houve correlação entre a embriogênese somática e regeneração de plantas in vitro (Tabela 1), o que permite inferir que a rota preferencial de regeneração não ocorreu por embriogênese. Também, os genótipos considerados sem capacidade regenerativa in vitro a partir de embriões maduros, como UFRGS 930572, foram regenerados a partir de segmentos da base da folha. A possibilidade de explorar um maior número de genótipos e regenerar plantas de uma maneira menos laboriosa e mais rápida fazem do explante base da folha um atrativo para a produção de plantas transgênicas.

\section{CONCLUSÕES}

O uso do explante base da folha em aveia possibilitou reduzir o tempo de regeneração de plantas para cinco meses e regenerar genótipos de aveia antes considerados sem habilidade para regeneração in vitro.

Não foi encontrada variabilidade entre os genótipos estudados quanto à capacidade de induzir calos embriogênicos e regenerar plantas a partir desse explante, e a não correlação entre a percentagem de embriogênese somática e regeneração de plantas permite inferir que a embriogênese não é o único caminho de regeneração a partir desse explante.

\section{AGRADECIMENTOS}

Os autores agradecem à FAPERGS pelo apoio financeiro e pela bolsa de iniciação científica para o desenvolvimento deste trabalho, e ao $\mathrm{CNPq}$ pela bolsa de mestrado concedida ao primeiro autor.

\section{REFERÊNCIAS BIBLIOGRÁFICAS}

BERED, F., SERENO, M.J.C.de M., CARVALHO, F.I.F.de., et al. Avaliação de embriogênese somática em cultivares de aveia (Avena sativa $\mathbf{L}$.). Ciência Rural, v.26, n.3, p.371375, 1996.

BERED, F., SERENO, M.J.C.de M., CARVALHO, F.I.F.de., et al. Regeneração de plantas de aveia a partir de calos embriogênicos e organogênicos. Pesquisa Agropecuária Brasileira, v.33, n.11, p.1827-1833, 1998.

BREGITZER, P.P., SOMERS, D.A., RINES, H.W. Development and characterization of friable, embriogenic oat callus. Crop Science, v.29, p.798-803, 1989.

BREGITZER, P.P., MILACH, S.C.K., RINES, H.W., et al. Somatic embryogenesis in oat (Avena sativa L.). In: BAJAJ, Y.P.S. Biotechnology in agriculture and forestry. New York : Springer- Verlag, 1995. Cap.I.5. p.53-62.
CARTER, O., YAMADA, Y., TAKAHASHI, E. Tissue culture of oats. Nature, v.241, n.3, p.1029-1030, 1967.

CUMMINGS, D.P., GREEN, C.E., STUTHMAN, D.D. Callus induction and regeneration in oats. Crop Science, v.16, p.465-470, 1976.

GLESS, C., LÖRZ, H., GÄRTNER-JÄHNE, A. Establishment of a highly efficient regeneration system from leaf base segments of oat (Avena sativa L.). Plant Cell Reports, v.17, p.441-445, 1998a.

GLESS, C., LÖRZ, H., GÄRTNER-JÄHNE, A. Transgenic oat plants obtained at high efficiency by microprojectile bombardement of leaf base segments. Journal of Plant Physiology, v.152, n.16, p.151-157, 1998b.

HANDEL, C.L., WAGNER, C.M., MILACH, S.C.K., et al. Transformação genética de cereais via Agrobacterium tumefaciens. Ciência Rural, v.27, n.2, p.359-365, 1997.

LAMB, C.R.C. Embriogênese somática, regeneração de plantas e transformação genética de genótipos brasileiros de aveia (Avena sativa L.); Porto Alegre, 2000. 98 p. Dissertação (Mestrado em Fitotecnia) - Curso de Pós-graduação em Fitotecnia, Universidade Federal do Rio Grande do Sul, 2000 .

LÖRZ, H., GÖBEL E., BROWN, P. Advances in tissue cultures and progress towards genetic transformation of cereals. Plant Breeding, v.100, p.1-25, 1988.

MURASHIGE, T., SKOOG, F. A revised medium for rapid growth bioassay with tobacco tissue cultures. Physiologia Plantarum, v.15, p.473-497, 1962.

RINES, H.W., McCOY, T.J. Tissue culture initiation and plant regeneration in hexaploid species of oats. Crop Science, v.21, p.837-842, 1981 .

SAS INTITUTE. SAS user guide. Cary : SAS Institute, 1998. p.521.

SOMERS, D.A., RINES, H.W., GU, W., et al. Fertile, transgenic oat plants. Biotechnology, v.10, p.1589-1594, 1992.

SOMERS, D.A., RINES, H.W., TORBERT, K.A., et al. Genetic transformation in Avena sativa L. In: BAJAJ, Y.P.S. Biotechnology in agriculture and forestry. New York : Springer- Verlag, 1996. Cap. II.3. p.178-190.

TORBERT, K.A., RINES, H.W., SOMERS, D. A. Transformation of oat using mature embryo-derived tissue cultures. Crop Science, v.38, p.226-231, 1998.

TORBERT, K.A., RINES, H.W., SOMERS, D.A. Use of paromomycin as a selective agent for oat transformation. Plant Cell Reports, v.14, p.635-640, 1995.

WERNICKE, W., BRETTELL, R. Somatic embryogenesis from Sorghum bicolor leaves. Nature, v.287,.n.11, p.138-139, 1980 .

ZHANG, S., ZHONG, H., STICKLEN, M.B. Production of multiple shoots from shoot apical meristems of oat (Avena sativa L.). Journal of Plant Physiology, v.148, p.667-671, 1996. 